\title{
CARACTERIZAÇÃO SOCIOECONỐMICA E EDUCACIONAL DO ESTUDANTE DE ENFERMAGEM NAS ESCOLAS DE MINAS GERAIS
}

\author{
Djair Daniel Nakamae* \\ Maria Rizoneide Negreiros de Araújo ** \\ Maria Lígia Mohallem Carneiro *** \\ Lúcio José Vieira **** \\ Suelene Coelho*****
}

NAKAMAE, D. D. et al. Caracterizaçăo socioeconómica e educacional do estudante de enfermagem nas escolas de Minas Gerais. Rev. Esc.Enf.USP, v.31, n.1, p. 109-18, abr. 1997.

Os autores fazem uma descrição do perfil comparativo dos estudantes de enfermagem provenientes das escolas mineiras, públicas e privadas. Concluem mostrando semelhanças e diferenças que caracterizam os dois grupos. Dão destaque às diferenças significativas que se referem à vida escolar, requisitos para o aproveitamento no ensino e a situação econômica dos estudantes. O aluno da escola privada está em desvantagem, entrou mais tarde na universidade, tem menos tempo para os estudos, a maioria deles trabalha, os pais têm menor instrução formal. Incentivam os colegas a darem continuidade com pesquisas de maior alcance.

UNITERMOS: Educação em enfermagem. Perfil do estudante de enfermagem. Escola de Enfermagem de Minas Gerais

\section{INTRODUÇÃO}

Preocupados com a melhoria de qualidade do processo educacional e acreditando que este se torna mais adequado na medida em que o educador conhece e leva em conta, criticamente, os dados relativos às características do educando, os autores desse estudo levantaram dados que integrarão a soma de informações capazes de abrir caminhos para futuras investigações em nível de mestrado na Escola de Enfermagem da Universidade Federal de Minas Gerais.

\footnotetext{
* Enfermeira. Prof. Titular Visitante da Escola de Enfermagem da Universidade Federal de Minas Gerais (EEUFMG)

** Enfermeira. Prof ${ }^{a}$. Adjunto da EEUFMG - Doutoranda na EEUSP

*** Enfermeira. Prof ${ }^{*}$. Assistente da EELFMG - Doutoranda na EEUSP

**** Enfermeiro. Prof. Auxiliar da EEUFMG - Mestrando na EEUFMG

**** Enfermeira. Prof ${ }^{*}$. Auxiliar da EEUFMG - Mestranda na EEUFMG
} 
Um exame mais detido indica que poucas vezes dados relativos ao aluno, na formulação do processo ensino-aprendizagem vem sendo levados na devida conta. Na maioria das vezes, todo um processo educativo tem sido realizado em função de determinantes de outra ordem, deixando em plano secundário as condições concretas do elemento humano, objeto desse processo.

Estudos dessa natureza vem sendo realizados por NAKAMAE em São Paulo, já há duas décadas. O primeiro deles realizou-se com amostras assemelhadas coletadas em 1973 e 1976. Confrontados esses achados, foram detectadas diferenças ocorridas no perfil socioeconômico e cultural dos estudantes que adentraram as escolas de enfermagem do Estado de São Paulo naquele período. Tendências significativas foram constatadas, mostrando uma progressiva qualificação do aluno. Tais achados levantaram questionamentos sobre a adequação da metodologia de ensino usada ao longo dos anos, tendo em conta as características dos estudantes em processo de transformação.

Para atualizar essas informaçōes, NAKAMAE e COSTA (1988) realizaram outro estudo, confrontando o perfil dos acadêmicos de escolas governamentais e particulares na região da Grande São Paulo. Foram detectadas diferenças significativas que caracterizam duas escolas distintas (públicas e privada), próprias de formações sociais marcadas pela divisão de classes sociais, como a brasileira.

Partindo das experiências acima mencionadas, NAKAMAE e colaboradores da Escola de Enfermagem da Universidade Federal de Minas Gerais consideraram oportuno aplicar os mesmos procedimentos dos estudos feitos em São Paulo na população de discentes das escolas de enfermagem do Estado de Minas Gerais. A dinâmica dos processos transcorridos nas realidades estudadas permitiu aos autores fazer uma leitura dos achados contextualizados no momento histórico de cada escola e agrupá-los, quando estes o permitissem, possibilitando uma visão da totalidade e da particularidade dessas instituições.

\section{OBJETIVOS}

Foi nessa perspectiva que os autores encontraram motivação para a presente investigação, que objetiva identificar dados concretos e atualizados que definam as características socioeconômicas e educacionais específicas do universitário que freqüenta os cursos de graduação das escolas de enfermagem do Estado de Minas Gerais no primeiro semestre de 1995. Busca-se, também confrontar as características dos estudantes de escolas públicas com as de escolas privadas. Com isso pretende-se obter subsídios que possibilitarão averiguar em estudos futuros as propostas metodológicas na prática do ensino da enfermagem. Estes resultados poderão também contribuir na composição do referencial da reformulação curricular das Escolas de Enfermagem de Minas Gerais, ora em 
discussão, para implantação acordada pela Portaria n. ${ }^{\circ}$ 1721/94 do Ministério da Educação, Cultura e Desportos.

\section{METODOLOGIA}

Trata-se de um estudo descritivo de natureza exploratoria, baseado no método estatístico quantitativo.

\section{Campo de pesquisa, população e amostra}

O Campo compõe-se de oito escolas de enfermagem existentes no Estado de Minas Gerais, Alfenas, Belo Horizonte (UFMG, PUC), Itajubá, Juiz de Fora, Passos, Pouso Alegre e Uberaba. O universo da pesquisa constituiu-se daquelas escolas que autorizaram o estudo. A amostra obedeceu a critérios básicos previamente estabelecidos. O primeiro consistiu em selecionar alunos cursando a última série. Escolheu-se esta série por ser terminal e constituída de estudantes com mais vivência universitária , mais categorizados portanto, a opinar sobre suas perspectivas profissionais e a transmitir o seu ponto de vista acerca do mercado de trabalho que os aguarda. O segundo critério foi o do aluno presente por ocasião da aplicação do questionário e não o universo dos estudantes matriculados. Obedecendo aos critérios referidos, os dados foram coletados pelos pesquisadores e auxiliares devidamente treinados. A coleta realizou-se em dias letivos regulares e em horários intercalados dentro do período de aula, a fim de atingir maior número de estudantes.

Os dados da amostra foram coletados por meio de um questionário contendo 32 perguntas (anexo), no qual se tomou por base quesitos aplicados nas pesquisas de NAKAMAE (1978 e 1988), que sistematizou rigorosamente, com auxílio das pesquisas de PASTORE e PEROSA (1971) e CASTRO (1968), os itens necessários, que foram agrupados nas categorias que se seguem: a) dados demograficos: idade, estado civil; Situação socioeconômica: mobilidade geográfica, nível de instrução dos pais, situação ocupacional dos pais; $b$ ) vida escolar: intervalo entre os cursos médio e superior, curso de segundo grau, freqüência a "cursinhos", vestibulares para outros cursos, freqüência a outro curso superior; c) situação econômica atual do estudante: ocupação remunerada, motivos que o levaram a isso, tipo de auxílio financeiro que recebe, contribuição para o orçamento familiar, posse de carro pelo estudante; d) requisitos para o aproveitamento escolar: adequação do trabalho ao curso, mínimo de horas semanais de trabalho, tempo médio semanal de aulas expositivas, seminários, aulas práticas e estágios, estudo em casa e na biblioteca, tempo gasto no percurso da residência à faculdade; e) aspiração e informação sobre a carreira: razões da opção pelo curso, auto-realização no curso, informação referentes às oportunidades ao mercado de trabalho, pretensão de exercício profissional no ano seguinte a formatura. 
Ao término do questionário acrescentou-se o tópico "comentário e observações", para permitir ao aluno expressar-se livremente após haver respondido a série de questões predeterminadas.

Adotou-se a sistemática de distribuir os questionários nas salas de aula e recolhê-los imediatamente após o seu preenchimento, não limitando o tempo disponivel para as respostas. Procurou-se motivar os estudantes explicando o prop6sito do estudo. As dúvidas foram respondidas à medida que surgiram e durante o preenchimento do instrumento.

Obedecendo os critérios referidos, realizou-se o estudo com uma amostra de $15 \%$ da população total de graduandos das oito escolas de enfermagem de Minas Gerais, o que representou $90 \%$ do universo dos que cursavam o último ano o que torna estatisticamente legítima a generalização dos resultados para esse universo.

\section{Tratamento dos dados}

Foram processados e tabulados obedecendo-se a distribuição de freqüência relativa e organizados em trinta e uma (31) tabelas e onze (11) gráficos. Após análise das informações assim sistematizadas, concluiu-se o estudo traçando o perfil do estudante das escolas envolvidas, tomando-se os valores mais significativos de cada tabela e gráfico.

\section{RESULTADOS E DISCUSSÃO}

O perfil do quartanista das escolas de enfermagem de Minas Gerais pode ser caracterizado na descrição sucinta que se apresenta a seguir

Dados demográficos: A grande maioria (88\%) dos estudantes amostrados é do sexo feminino. Predominam os solteiros $(80 \%)$, mas os casados já contam quase um quarto nos dois tipos de instituições. Os alunos das escolas públicas (80\%) estão na faixa de idade mais jovem e com seqüência de escolaridade mais próxima do usual (20 a 23 anos), enquanto que os de escolas privadas enquadram-se em maior proporção $(70,3 \%)$ nas faixas etárias mais altas com atraso considerável na vida escolar.

Situacão socioeconômica familiar: A mobilidade geográfica das três gerações 6 descrita na predominância dos avós brasileiros (que ultrapassa três quartos em ambos os tipos de instituições), na quase totalidade dos pais e na totalidade dos estudantes que é de nascidos no Brasil. Dentre os poucos avós e pais estrangeiros $(8 \%)$, predominam os de origem latina. 
A migração de estudantes de outros estados brasileiros para as escolas mineiras é pequena, aproximando-se de um quarto do total. Todavia, essa proporção eleva-se um pouco mais nas instituições privadas, com destaques para São Paulo, Goiás, Distrito Federal e Ceará. Um pouco mais da metade dos alunos $(60 \%)$ reside com familiares durante o ano letivo. É variado o nível de instrução dos pais. Os de escola pública atingiram escolaridade mais elevada, enquanto que na escola privada mais da metade tem instrução elementar e poucos conseguiram nivel superior. Metade dos pais trabalha por conta propria, com predomínio pequeno dos donos de firmas, nas escolas públicas. É mais elevado o número de mães que não trabalha fora de casa, mas entre as que o fazem, estão em maioria as que trabalham por conta própria ou são funcionárias públicas. Mais da metade $(61,2 \%)$ dos alunos de escolas privadas trabalhava antes de ingressar na faculdade, porém observa-se um número menor deles $(40,4 \%)$ nas faculdades públicas. Após ingresso no curso, aumenta um pouco a proporção dos primeiros $(68,6 \%)$ e quase nada se altera na dos segundos $(41 \%)$. A quase totalidade (90\%-86\%) dos pais tem residência própria, sendo pequena a diferença entre os dois grupos.

Vida escolar: Predominam nas escolas públicas $(44,7 \%)$ os acadêmicos que ingressaram com idade entre 20 e 23 anos. É alto entre estes o número dos que completaram o curso científico no segundo grau $(64,6 \%)$, o que lhes dá grande vantagem em relação aos alunos das instituições privadas, onde mais da metade $(53,7 \%)$ concluiu cursos profissionalizantes e alguns $(3,3 \%)$ apenas os supletivos. Contam-se entre esses últimos grande número dos que se atrasaram em demasia para ingressar na escola de enfermagem. Mais da metade deles $(63,4 \%)$, nas escolas públicas, ingressou direto ou esperou no máximo dois anos para isso $(35,4 \%)$. A grande maioria $(79,5 \%$ e $83,5 \%)$, nas duas instituições, prestou vestibular para enfermagem apenas uma vez. Grande proporção deles, na escola pública $(62,1 \%)$, acusa freqüência a cursos pré-vestibulares. Esse número cai bastante entre os alunos das escolas privadas $(36,4 \%)$. Quase a totalidade $(80,7 \%)$, nas instituições públicas, prestou vestibular para outro ramo. Embora quase a metade deles ( $46 \%)$ tenha sido aprovada, apenas pequena minoria(l,5 e 5,3\%) freqüenta outro curso superior. Dos que foram aprovados em outras áreas, o maior índice de aprovação nas escolas privadas foi em ciências humanas, enquanto que nas escolas públicas predominou a grande aprovação na área de biomédicas, com ênfase nos cursos de medicina, odontologia e biologia.

Situacão econômica atual dos estudantes: Exercem ocupação remunerada pouco menos da metade(41\%) dos acadêmicos de escolas públicas, já na escola privada quase três quartos $(68,6 \%)$ o fazem. Em ambas as escolas declararam, em maior proporção, que trabalham pela necessidade de remuneração e experiência. A maior proporção $(48,8 \%)$, na escola privada, recebe salário, enquanto que a maioria $(48,4 \%)$ da escola pública recebe mesada, e somente os primeiros $(20,7 \%)$ 
recebem crédito educativo. Prevalecem em ambos os grupos (55 e 59\%) os que não dispõem de carro para uso próprio. Entre os que trabalham, mais da metade (63\%) na escola pública não contribui nas despesas familiares contra a metade, nas instituições particulares, que contribui sem ser o único responsável.

Grande número (34 e 41\%) tem jornada de trabalho em média de 18 a 32 horas semanais, em ambos os grupos, a maior parte dos estudantes (53 e 65\%) estuda em casa ou na biblioteca menos de dez horas semanais. Quanto ao tempo gasto no percurso até a faculdade, predominam nos dois grupos os que gastam menos de trinta minutos, destacando-se mais os de escola privada (44 e 68\%).

Aspiração e informação sobre a carreira: Nos dois grupos prevalece (59,6 e $59,5 \%)$ a opinião dos que alegaram ser a "inclinacão pela profissão" o motivo principal de sua opção pelo curso, confirmando os achados de NAKAMAE (1976, 1988). Todavia, em segundo plano, estão os que referiram como motivo a "não aprovação em outro curso", sendo essa uma afirmação prevalente entre os acadêmicos de escola pública (12 e 10\%). Embora uma pequena parcela, nos dois grupos, já se perceba frustada em sua carreira profissional antes de nela ingressar, esse número de alunos é bem maior do que nos achados de NAKAMAE $(1976,1988)$. Contudo, predominam ainda (84 e $85 \%)$ os que se dizem satisfeitos com a escolha, muito embora alguns não a desejassem no início do curso. A grande maioria, nos dois tipos de instituições, pensa que terá ótimas (16 e 21\%) ou boas (68 e 59\%) oportunidades de emprego. Parcela razoável demonstra percepção realista quanto à faixa salarial, que era compatível com o salário pago pelo mercado naquele período do ano quando foram questionados. Os alunos das escolas públicas, porém, demonstram percepção mais aguçada sobre a flutuação dos salários. É bastante elevado o número dos que pretendem exercer a profissão em serviços hospitalares, no ano seguinte ao da formatura (72 e 78\%).

No confron to do perfil do estudante de escolas públicas e de escolas privadas foi possivel detectar pontos de semelhanças (convergências) e de diferenças (divergências). Dentre as principais convergências destacam-se:

- Prevalecem os alunos do sexo feminino e os solteiros, mas os casados já se aproximam de um quarto nos dois tipos de instituições.

- A maioria dos avós, a quase totalidade dos pais e a totalidade absoluta dos estudantes é de nascidos no Brasil.

- A maior parte dos alunos reside com seus familiares durante o ano letivo.

- É mais elevado o número de mães que não trabalha fora de casa. Entre as que o fazem estão em maioria as que trabalham por conta própria ou são funcionárias públicas.

- A quase totalidade dos pais tem residência própria.

- Predominam os estudantes que prestaram vestibular para enfermagem apenas uma vez. 
- Uma maior proporção trabalha pela necessidade de remuneração e aquisição de experiências.

- $\quad$ Prevalecem os que dizem não dispor de carro para uso próprio.

- A grande maioria dos que trabalham diz ter jornada, em média, de dezoito a trinta e duas horas semanais.

- Predominam os que gastam menos de trinta minutos no percurso de sua residência à escola e/ou do trabalho à escola.

- Prevalece a opinião dos alunos que alegaram ser a "inclinação pela profissão" o motivo principal de sua opção pelo curso.

- Uma pequena parcela, nos dois grupos, já se diz frustrada em sua carreira profissional antes de nela ingressar.

- Predominam os que se dizem satisfeitos com a escolha, muito embora alguns não a desejassem no início do curso.

- A grande maioria pensa que terá ótimas ou boas oportunidades de emprego ao concluir o curso.

- E E bastante elevado o número dos que pretendem exercer a profissão em serviço hospitalar, no ano seguinte a formatura.

No que diz respeito ás divergências, verifica-se que:

- Nas escolas privadas enquadram-se os alunos nas faixas etárias mais altas e com atraso considerável na sua vida escolar.

- Nas escolas públicas os pais atingiram, em maior proporção, nível de escolaridade mais elevado do que nas escolas privadas, onde mais da metade tem instrução elementar e, bem poucos, o nível superior.

- Metade dos pais trabalha por conta própria, mas há predomínio dos donos de firmas nas escolas públicas.

- Mais da metade dos alunos de escolas privadas trabalhava antes de ingressar no curso e esse número reduziu-se um pouco após ingresso, todavia, era bem menor nas escolas públicas e quase não se alterou após o ingresso.

- Nas escolas públicas predomina a escolaridade normal e grande número completou o curso científico; nas privadas, mais da metade concluiu cursos técnico-profissionalizantes e alguns o supletivo, atrasando-se em demasia para ingressar no curso de enfermagem. 
- Mais da metade, nas escolas públicas, ingressou direto na universidade ou esperou no máximo dois anos e grande número acusa frequêencia a cursos pré-vestibulares; nas privadas esse número se reduz significativamente.

- Nas escolas públicas, quase a totalidade prestou vestibular para outra área universitária, aproximadamente a metade deles foi aprovada mas, minoria quase insignifican te freqüenta outro curso superior, predominou a aprovação na área de ciências biomédicas; nas escolas privadas quase a metade prestou exame para outro curso, metade deles foi aprovada; em maior número na área de ciências humanas e percentagem maior que os primeiros está dando continuidade ao curso.

- Nas escolas públicas menos da metade exerce ocupação remunerada; nas privadas quase três quartos trabalham.

- A maior proporção deles, nas escolas públicas, recebe mesada da família; nas escolas privadas grande maioria recebe salário e crédito educativo.

- Dentre os trabalhadores das escolas públicas, dois terços não contribuem para as despesas familiares; nas instituições privadas, metade contribui sem ser o único responsável.

- O segundo maior motivo da opção pela enfermagem refere-se à "não aprovação em outro curso", onde os alunos das escolas públicas predominam sobre as outras.

- Parcela razoável dos amostrados demonstra percepção realista quanto à faixa salarial do enfermeiro, porém nas escolas públicas há uma percepção mais aguçada quanto à flutuação desse valor.

\section{CONSIDERAÇÕES FINAIS}

Respondendo aos objetivos iniciais, a pesquisa atual faz uma descrição do perfil comparativo dos estudantes de enfermagem provenientes dos dois tipos de escolas mineiras, as públicas e as privadas. Conclui mostrando as semelhanças e as diferenças que caracterizam os dois grupos. Algumas dessas diferenças mostram-se notadamente significativas e merecem destaque especial nesta parte do estudo.

Nesse sentido, observa-se que os aspectos relativos à vida escolar, requisitos para o aproveitamento e a situação econômica do estudante confluem para pontos comuns e encaminham para as considerações abaixo.

Nas escolas privadas, um número apreciável dos estudantes amostrados está em desvantagem quando comparado aos seus colegas das escolas públicas. Ao atraso que sofreram no ingresso para a universidade soma-se a pouca 
disponibilidade de tempo para o estudo e a leitura fora do periodo de atividade escolar, pois grande proporção deles já trabalhava e número quase igual continua trabalhando após o início do curso. Trabalham numa jornada de até quarenta horas semanais e são os que, em número maior, contribuem para a renda familiar. A isso soma-se o fato de que significativa porcentagem deles concluiu o segundo grau em cursos técnico-profissionalizantes ou supletivos e provêm de famílias onde prevalecem pais com instrução elementar.

Como se pode constatar, trata-se de uma clientela que, além de freqüentar escolas pagas, apresenta aspectos socioeconômicos e educacionais que dificultam, em parte, 0 aproveitamento num curso universitário. Isso denuncia uma situação precária para o rendimento escolar, associada a uma sobrecarga física e mental para esses estudantes. Pela situação descrita infere-se que o conhecimento do perfil do aluno que procura o curso de enfermagem é fundamental para estudar novas propostas metodologicas no ensino, que sejam mais compatíveis com essa realidade.

Parece oportuno atentar para a oferta de vagas nas escolas públicas (47\%) que se mostra menor do que nas escolas privadas (53\%). Acrescenta-se a isso um maior rigor na forma dos exames vestibulares, o que dificulta sobremaneira os candidatos que provêm de uma classe social com possibilidades de escolaridade que lhes dão desvantagens e os deslocam para o ensino privado. E interessante observar que a oferta de vagas nas escolas públicas é menor na entrada, porém o número de matriculados no último ano do curso mostra-se maior nesse tipo de estabelecimento. Desse fato depreende-se que muitos alunos das escolas privadas não conseguem finalizar o curso, evadindo-se. Um estudo para detectar esse aspecto seria muito oportuno.

Os dados encontrados reiteram os pontos defendidos por NAKAMAE, (1986), com base em autores como FREITAG (1984), SNYDERS (1977) e outros, relativos ã existência, em formações sociais marcadas pela divisão de classes, como a brasileira, de duas escolas distintas.

Essas constatações mostram a necessidade de buscar medidas que promovam a reformulação do ensino nos dois tipos de instituições, mas com ênfase nas escolas particulares, procurando novas posturas na metodologia do ensino que sejam mais realistas frente às condições socioeconômicas e educacionais dos estudantes que procuram os cursos de enfermagem. Será necessário também precaver-se de não incidir na pressuposição de que o ensino oferecido pelos estabelecimentos governamentais seja, por isso, modelar.

Para finalizar, volta-se à tese inicial de que um processo de educação na enfermagem deve fundar-se primeiramente na identificação das características do estudante, a fim de que estas sirvam de subsidios que possibilitarão averiguar, em estudos que lhe dêem continuidade, as condições reais de aplicabilidade das práticas didáticas tradicionais, bem como as novas propostas na área da metodologia do ensino de enfermagem.

Cabe ressaltar que esta pesquisa visa a dar subsídios para outras, uma já em andamento, abrindo linha de pesquisa que analise novas técnicas de ensino 
que avalie a situação de estudantes com pouca disponibilidade de tempo para o estudo e leituras fora do período escolar.

Este trabalho terá portanto, alcançado os seus objetivos se servir de ponto de partida ou incentivo para outros estudos que dêem continuidade com pesquisas em maior alcance, dando respostas mais concretas as outras questões referentes ao como, o quê e para quê ensinar. Sendo a educação um processo dinâmico, não se pretende chegar a respostas definitivas as questões acima. Mas, iniciando o trabalho pedagogico em bases mais sistematizadas, a tarefa docente para as gerações futuras poderá ser mais produtiva em face das mudanças que forem ocorrendo no perfil dos estudantes, que sofre alterações em função de mudanças mais amplas no contexto social.

\section{REFERÊNCIAS BIBLIOGRÁFICAS}

CASTRO, C.L.M. Caracterizacão sócio-econômica do estudante universitário. Rio de Janeiro, Centro Brasileiro de Pesquisas Educacionais, 1968.

FREITAG, B. Escola, estado e sociedade. 4.ed. São Paulo, Moraes, 1984.

NAKAMAE, D.D. Subsídios para a caracterizaçáo do estudante de enfermagem nas escolas do Estado de São Paulo. Ciência e Cultura v.27, n. 7, p. 595-9, 1975. Suplemento/Apresentado ao $27^{\circ}$ Reunião Anual da SBPC, Belo Horizonte, 1975-Anais/

NAKAMAE, D.D.; COSTA, M.L.S. Semelhanças e diferenças do perfil de estudantes em escolas governamentais e particulares. Rev. Paul. Enf., v.12, n.2, p.72-9, 1993.

PASTORE, J.; PEROSA, G.G. O estudante universitário em São Paulo. São Paulo, Instituto de Pesquisas Econômicas da USP (IPE), 1971.

SNYDERS, G. Escola, classe e luta de classe. Lisboa, Moraes, 1977.

NAKAMAE, D.D. et al. Educational and socio-economic characterization of nursing student in the schools of Minas Gerais. Rev.Esc.Enf.USP, v.31, n.1, p. 109-18, apr. 1997.

This study compare the profile of nursing students from public and private schools located in the State of Minas Gerais, Brazil. It shows the similarities and differences between the two groups. The results show that the most significant diferences are related to school life, requisites for learning and the economic situation of the students. The private schools student is in disadvantage, he enters at university later, disposes less time to study, the majority works, his parents have less regular instruction. This results can be used by other professionals to continue this kind of research with a broader scope.

UNITERMS: Education in nursing. Profile of nursing student. 